\title{
EDUCAÇÃO PROFISSIONAL E A INCLUSÃO DE PESSOAS COM DEFICIÊNCIA: UM MAPEAMENTO SISTEMÁTICO
}

\author{
Fernanda Souza da Silva*, Laíse do Nascimento Paula, Talita Soares Lago Duarte Costa, \\ Francisco Adelton Alves Ribeiro, Alvaro Itaúna Schalcher Pereira \\ *E-mail: fernanda_s13@hotmail.com \\ Instituto Federal de Educação, Ciência e Tecnologia do Maranhão \\ DOI: $10.15628 /$ rbept.2020.8199
}

Artigo submetido em jan/2019 e aceito em jan/2020

\begin{abstract}
RESUMO
A inclusão de pessoas com deficiência na educação profissional vem ganhando espaço ao longo dos últimos anos, contribuindo para a inserção social e, principalmente, profissional no mercado de trabalho. Para analisar os debates discutidos nessa temática, foi conduzido um mapeamento sistemático, por meio das bases de dados Scielo, Scopus e Web of Science. Inicialmente foram encontrados 303 artigos, sendo que apenas 11 atenderam os critérios de inclusão e exclusão determinados. Os resultados das análises apontam para importância da oferta de uma educação profissional de qualidade aliada a ações de inclusão, para a independência, autonomia e emancipação do discente com deficiência, oportunizando que o mesmo possa ter uma vida significada de sentido por meio do trabalho e condições de ingressar no mercado em melhores vagas e responsabilidade profissional.
\end{abstract}

Palavras-Chave: Ensino. Formação. Trabalho.

\section{PROFESSIONAL EDUCATION AND THE INCLUSION OF PEOPLE WITH DISABILITIES: A SYSTEMATIC MAPPING}

\begin{abstract}
The inclusion of people with disabilities in professional education has been expanding over the last few years, contributing to the social insertion and, especially, professional insertion in the labor market. To analyze the discussed debates in this theme, a systematic mapping was conducted through the Scielo, Scopus and Web of Science databases. In the first place 303 articles were found and only 11 met the inclusion and exclusion criteria. The results of the analyzes point to the importance of offering a quality professional education with inclusion actions for the independence, autonomy and emancipation of disabled students allowing them to have a meaningful life through employment and conditions to enter the labour market in better vacancies and professional responsibility.
\end{abstract}

Keywords: Teaching. Formation. Job. 


\section{INTRODUÇÃO}

Quando se trata de inclusão e educação profissional, estamos nos referindo a dois direitos constitucionais fundamentais: o direito à educação e o direito ao trabalho. Nesse contexto, a inclusão é mais que uma inserção de espaço, torna-se uma missão social que visa à garantia de direitos, assegurando o exercício de cidadania. A história da inclusão da pessoa com deficiência na educação profissional decorre dos caminhos da inclusão na educação em geral, e as ações devem ser analisadas, discutidas e implantadas como fator de inserção do discente na vida social e no mundo do trabalho, por meio do aprendizado de qualidade.

Apesar dos avanços nas políticas públicas de inclusão, ainda é grande a exclusão da pessoa com deficiência no mercado de trabalho. Visando equiparar as desigualdades, o Brasil aprovou a lei de cotas que institui a porcentagem mínima de $2 \%$ a $5 \%$ de pessoas com deficiência contratadas para cada empresa, no entanto, a lei de cotas institui, mas não aborda o processo de formação profissional dessas pessoas, o que dificulta a sua eficiência.

Historicamente o processo de formação profissional das pessoas com deficiência teve seu foco na perspectiva assistencialista, o que colocou em dúvida a capacidade, a independência e a autonomia para que atuem como sujeitos ativos no mundo, limitando suas participações na inclusão, na educação e no trabalho em detrimento da garantia dos seus direitos. Assim, esta pesquisa perpassa pela discussão da relevância de estudos sobre a inclusão na educação profissional como modalidade de ensino para integrar o discente com deficiência no mundo do trabalho com preparação adequada para o exercício profissional.

O presente artigo, de caráter descritivo, consiste em uma revisão bibliográfica com objetivo de identificar as discussões no processo de inclusão de pessoa com deficiência na formação profissional. O texto está estruturado em quatro partes. A primeira parte, o referencial teórico, faz um levantamento do percurso histórico das políticas públicas de inclusão e a pressão dos movimentos sociais para sua efetivação, a fim de demonstrar o processo histórico e a totalidade dos fatos em que a inclusão na educação profissional se encontra, dialogando com processos contraditórios de inclusão e exclusão. A segunda parte é relativa à metodologia do mapeamento sistemático aplicado na identificação de dados relacionados a essa pesquisa utilizando, para aprofundamento das discussões, buscas de artigos realizadas nas bases de dados Scielo, Scopus e Web of Science. O terceiro momento consiste na análise de dados dos artigos escolhidos de acordo com as perguntas norteadoras da pesquisa, que questionam quais os assuntos abordados recentemente sobre o tema e como essas pesquisas relacionam a formação profissional da pessoa com deficiência e o mundo do trabalho. Por 
último, serão apresentadas as considerações finais sobre as análises refletidas nesse trabalho.

\title{
2 INCLUSÃO DA PESSOA COM DEFICIÊNCIA NA EDUCAÇÃO
}

A educação da pessoa com deficiência no Brasil vem sido marcada, ao longo de seu desenvolvimento, por políticas e movimentos de exclusão com ações assistencialistas ou de segregação, mas também por tentativas de inclusão que ganham força a partir da década de 90, como afirmam Rocha, Amorim e Ferreira (2018, p. 508).

\begin{abstract}
Duas grandes vertentes têm marcado a construção das políticas públicas educacionais para as pessoas com deficiência no Brasil. A primeira revela uma concepção assistencialista com a criação de instituições especializadas com ambientes únicos para a aprendizagem desses sujeitos. A segunda, no entanto, aponta para uma sociedade inclusiva que vem contribuindo significativamente para a alteração das políticas sociais, buscando assegurar o direito da pessoa com deficiência, bem como a sua matrícula nas classes comuns.
\end{abstract}

A partir da Constituição Federal do Brasil de 1988, a educação passa a ser promulgada como Direito Social e de todos, contribuindo para o progresso das políticas de inclusão da pessoa com deficiência no sistema escolar brasileiro. A Lei de Diretrizes e Bases da Educação Brasileira - LDBEN, Lei no 9.394 de 20 de dezembro de 1996, reforçou a implementação da inclusão quando trouxe em seu inciso III, do Artigo $4^{\circ}$, a garantia de "atendimento educacional especializado gratuito aos educandos com necessidades especiais, preferencialmente na rede regular de ensino" (redação posteriormente alterada pela Lei $n^{\circ}$ 12.796, de 2013), entendendo que, ter a educação inclusiva incluída em políticas de abrangência nacional e de relevância histórica para mudanças consideráveis na educação, são conquistas de direitos que demonstram o avanço do processo democrático no país, e no que tange à educação e inclusão de grupos discriminados.

No ano de 2001, foi criado o Plano Nacional de Educação - PNE, por meio da Lei no 10.172/2001 que aborda, no capítulo 8, sobre a educação especial, apontando alguns dados, tendências da educação especial no Brasil e sobre a inclusão dentro do espaço formal de aprendizagem escolar, demonstrando a importância da escola inclusiva para a inserção da pessoa com deficiência, considerando que "o grande avanço que a década da educação deveria produzir será a construção de uma escola inclusiva que garanta o atendimento à diversidade humana" (BRASIL, 2001a).

Entende-se por inclusão a garantia, a todos, do acesso contínuo ao espaço comum da vida em sociedade, sociedade essa que deve estar orientada por relações de acolhimento à diversidade humana, de aceitação das diferenças individuais, de esforço coletivo na 
equiparação de oportunidades de desenvolvimento, com qualidade, em todas as dimensões da vida (BRASIL, 2001b, p. 20).

Assim, a inclusão no ambiente escolar deixa de ser apenas educacional e passa também a ser social, permitindo o incluir e o integrar com outras pessoas, fazendo com que as pessoas com deficiência sintam-se pertencentes a esse local, valorizando-os, respeitando-os, permitindo sua emancipação e autonomia para seguirem uma vida não segregada do mundo e construindo uma sociedade mais justa e solidária, como afirma Marques (1997, p. 22):

O caminho para a superação desta questão está na busca e no encontro de um sentido para a existência humana, cujo sujeito, o homem, não está determinado pela sua condição física, mental ou sensorial, mas principalmente por seu modo de ser, autêntico e único.

Incluir a pessoa com deficiência em todos os espaços e modalidades de ensino, garantindo a equidade e a qualidade, permite a construção de um ser social a partir da educação em uma perspectiva de integração em sociedade. Segundo Tezani (2004, p. 58) a educação na escola inclusiva é "o somatório de processos formativos que acontecem na sociedade, mediante interação com a família, convivência humana no trabalho, no ensino, na pesquisa, nos movimentos sociais e nas manifestações culturais", além de propiciar conhecimentos para o ingresso no mundo do trabalho, podendo construir uma vida com autonomia financeira e pessoal, processo esse que também atende ao desenvolvimento do capital, quando forma seres produtivos.

Nesse sentido, a formação profissional inclusiva na educação profissional, quando de qualidade, torna-se fundamental para a preparação para o mundo do trabalho, pois possui carga horária menor quando comparado ao ensino superior, podendo ser concomitante com o ensino médio, atendendo também a melhoria da subsistência do deficiente ou de sua família, já que, na teoria, o discente depois de formado está apto a exercer uma profissão. Para entender o papel da educação profissional inclusiva para a formação profissional da pessoa com deficiência, reflexões serão abordadas a seguir.

\section{EDUCAÇÃO PROFISSIONAL E INCLUSÃO: POSSIBILIDADES PARA O MUNDO DO TRABALHO.}

A educação profissional também passa por políticas e ações de exclusão da pessoa com deficiência, assim como a educação na totalidade, visto que faz parte dela, e só vai ganhando importância e força quando, pelo desenvolvimento do país, as classes dominantes começam a sentir a necessidade de uma formação de mão de obra adequada para produzir para o capitalismo através de uma formação (JANNUZZI, 2004). 
A inclusão na educação profissional aparece nos movimentos sociais que pressionam as políticas para sua efetivação e aumentam o crescimento de debates e tentativas de legislações e orientações nesse sentido. Em 1996, a educação profissional foi colocada como parte da reforma da educação na LDBEN de 1996, destacando o Art. 59, inciso IV, que abrange a responsabilidade do sistema de ensino assegurando a pessoa com deficiência:

IV - Educação especial para o trabalho, visando a sua efetiva integração na vida em sociedade, inclusive condições adequadas para os que não revelarem capacidade de inserção no trabalho competitivo, mediante articulação com os órgãos oficiais afins, bem como para aqueles que apresentam uma habilidade superior nas áreas artística, intelectual ou psicomotora (BRASIL, 1996).

Outro programa que mostra a relevância e fortalecimento do movimento de inclusão na educação profissional e no trabalho é o Plano Nacional de Formação Profissional - PLANFOR, da Secretaria de Formação de Desenvolvimento Profissional - SEFOR, do Ministério do Trabalho, que, segundo o Decreto ํㅜ 3.298, de 20 de dezembro de 1999, que regulamenta a Lei n- 7.853, de 24 de outubro de 1989, dispõe sobre a Política Nacional para a Integração da Pessoa Portadora de Deficiência, consolida as normas de proteção, e dá outras providências, tem como objetivos:

\begin{abstract}
Art. 45, Parágrafo Único, I - criar condições que garantam a toda pessoa portadora de deficiência o direito a receber uma formação profissional adequada; II - organizar os meios de formação necessários para qualificar a pessoa portadora de deficiência para a inserção competitiva no mercado laboral; e III - ampliar a formação e qualificação profissional sob a base de educação geral para fomentar o desenvolvimento harmônico da pessoa portadora de deficiência, assim como para satisfazer as exigências derivadas do progresso técnico, dos novos métodos de produção e da evolução social e econômica. (BRASIL, 1999).
\end{abstract}

Essas mudanças na visão do paradigma da inclusão da pessoa com deficiência na educação profissional demonstram a importância que ela passa a ter no Brasil, mas ainda assim com desafios que voltavam à educação para uma perspectiva tecnicista e somente para o trabalho, desvinculada da educação básica. Na própria LDBEN de 1996, quando aparecia no artigo, Art. $36, \S 4^{\circ}$ "A preparação geral para o trabalho e, facultativamente, a habilitação profissional, poderão ser desenvolvidas nos próprios estabelecimentos de ensino médio ou em cooperação com instituições especializadas em educação profissional" (revogado pela Lei no 11.741, de 2008), e como ainda está no Art. 40. "A educação profissional será desenvolvida em articulação com o ensino regular ou por diferentes estratégias de educação continuada, em instituições especializadas ou no ambiente de trabalho", abriu possibilidades de preparação para a habilitação profissional de forma facultativa, sendo esta articulada com o ensino regular ou não. 
$\mathrm{Na}$ prática, acabou pendendo para a separação do ensino médio da educação profissional no meio de políticas neoliberais do governo da época, de Fernando Henrique Cardoso, permitindo o fortalecimento da iniciativa privada, sem controle da qualidade dos cursos, contribuindo para a dualidade do tipo de educação oferecida por classes sociais e econômicas, mas garantindo que os pobres e excluídos se tornassem produtivos com um mínimo de qualificação para acompanhar o desenvolvimento da indústria, "já que, no projeto neoliberal, os objetivos no plano educacional estão vinculados à formação de uma força de trabalho com um nível mais alto de conhecimento, apta e flexível para acompanhar as exigências das novas tecnologias" (CAIADO, 2003, p. 16), mas sem levar em conta a qualidade da profissionalização e como estavam sendo inseridos no mercado, diferentemente de quem poderia arcar com uma educação de qualidade, fosse para o trabalho, fosse para estudar no ensino superior.

Nos anos 2000, o Programa TEC NEP - Educação, Tecnologia e Profissionalização de Pessoas com Necessidades Especiais, da Secretaria de Educação Profissional e Tecnológica - SETEC, do Ministério da Educação - MEC, fortaleceu a inclusão de pessoas com deficiência na educação profissional e no mundo do trabalho na Rede Federal de Educação Profissional, Científica e Tecnológica, com "o objetivo de modificar o contexto das instituições da rede federal, disseminando conceitos, divulgando experiências, sensibilizando as comunidades escolares, para a questão das necessidades especiais" (BRASIL, 2005, p. 11), articulando uma série de ações para o melhor desenvolvimento e apoio aos discentes com deficiência.

Em 2004, foi criado o Decreto n 5.154 , que possibilita a integração do ensino médio à educação profissional, permitindo a formação profissional com a propedêutica, construindo assim, e aqui no caso da pessoa com deficiência, um ser humano com uma formação geral que o possibilita ter condições de ter uma educação de qualidade com conhecimentos articulados, seja para continuar seus estudos ou ingressar no mundo do trabalho.

\footnotetext{
Assim, a política de ensino médio foi orientada pela construção de um projeto que supere a dualidade entre formação específica e formação geral e que desloque o foco dos seus objetivos do mercado de trabalho para a pessoa humana, tendo como dimensões indissociáveis o trabalho, a ciência, a cultura e a tecnologia (MOURA; GARCIA; RAMOS, 2007, p. 6).
}

O TEC NEP teve até junho de 2011, ações de preparação da Rede Federal de Educação Profissional, Científica e Tecnológica no sentido de acolher pessoas com deficiência na formação inicial e continuada, técnica, tecnológica e de pós-graduação e formação com êxito para o mercado de trabalho (NASCIMENTO; FARIA, 2013, p. 13), com destaque para a criação dos Núcleos de Apoio às Pessoas com Necessidades Educacionais Especiais - NAPNEs, dentro das instituições da Rede de Educação Profissional e Tecnológica, com o objetivo de "criar cultura de educação para convivência, aceitação da adversidade, para eliminação das barreiras arquitetônicas 
atitudinais e educacionais" (BRASIL, 2005, p. 14), refletindo na formação do discente com deficiência.

Cabe aqui destacar que a inclusão, para ser efetivada, necessita de ações conjuntas entre governo, políticas e ações na comunidade escolar de forma contínua, como formação de professores, adaptações metodológicas e pedagógicas, infraestrutura, em que se faz necessário o debate, estudos e pesquisas relacionados ao assunto, considerando que, além da relevância e do impacto social da educação inclusiva, a educação profissional continua a passar por mudanças no contexto atual. Em 2017, o Decreto no 5.154/04 foi revogado pela Lei ํo 13.415/ 2017, chamada a "Reforma do Ensino Médio", que também altera o ensino médio integrado à educação profissional, correndo o risco de haver a desarticulação dos mesmos nas instituições que já haviam avançado nesse sentido, podendo constituir em uma forma de retrocesso que impacta a todos, principalmente aqueles que já possuem uma história de exclusão no que diz respeito ao acesso à educação comum e igualitária e ao mundo do trabalho, como afirmam Costa e Oliveira (2017, p. 8):

\begin{abstract}
Isso se traduz no risco de institucionalizarem-se escolas de formação propedêutica para prosseguimento dos estudos e escolas puramente técnicas, cujos egressos não serão considerados público para o ensino superior, qualificando-se apenas para atender à demanda posta por um eixo precarizado do mercado de trabalho.
\end{abstract}

Apesar do progresso na inclusão da pessoa com deficiência na educação profissional, deve-se considerar que ao preparar para o trabalho, o discente necessita receber uma formação de qualidade que o capacite a exercer funções de responsabilidade dentro da sua área de formação, desconstruindo a barreira do preconceito e do incluir somente com atendimento à lei, sem considerar que ali há um profissional capacitado para ocupar uma vaga de trabalho.

De acordo com a Relação Anual de Informações Sociais - RAIS, anobase 2017, do Ministério do Trabalho:

Em 2017, houve crescimento no estoque de empregos formais das pessoas com deficiência. $\mathrm{O}$ contingente de pessoas com deficiência (PCD) empregadas totalizava 441,3 mil vínculos empregatícios, equivalente a $1,0 \%$ do estoque total. Em relação ao ano de 2016, houve expansão de $+22,8$ mil empregos, equivalente a $+5,5 \%$ (BRASIL, 2017).

Os dados revelam que a inclusão no mercado de trabalho aumentou, mas se faz necessário o acompanhamento da forma como estão sendo inseridos e do reflexo da educação no preenchimento de vagas que correspondem ao seu nível de instrução e na área desejada. Pode-se analisar que a ausência de pessoas com deficiência devidamente qualificadas profissionalmente é considerada uma barreira para as contratações, até 
mesmo para ocupação de vagas da base da pirâmide organizacional (SCHWARZ; HABER 2009), o que reflete na importância da educação profissional ser ofertada de forma planejada e inclusiva para ser de qualidade, sendo relevantes estudos e debates sobre as diversas formas de inclusão e todo o seu viés, além do incentivo nessa inserção pelas empresas e programas governamentais.

\section{METODOLOGIA}

O presente trabalho, de caráter descritivo, através de revisão bibliográfica de obras e pesquisas relacionadas ao tema proposto, procurou demonstrar a importância da inclusão de pessoas com deficiência na educação profissional para sua formação e inserção no mundo do trabalho e o desenvolvimento desse processo.

O método utilizado para a pesquisa foi o mapeamento sistemático, que de acordo com Rocha, Nascimento e Nascimento (2018, p. 3), é "um conjunto concreto de dados e conhecimentos sobre um determinado assunto", que possibilita analisar debates sobre um objeto de pesquisa e extração de dados do mesmo. A pesquisa deste trabalho foi baseada no modelo de Petersen et al. (2008), adaptando-o quando necessário, que sistematiza o processo em cinco etapas, que serão respondidas a seguir: 1 - Definição das questões de pesquisa; 2 - Realização da pesquisa de estudos primários; 3 - Utilização de critérios de inclusão e exclusão; 4 - Classificação dos artigos; 5 - Extração de dados. A análise de dados será realizada em capítulo separado.

As etapas foram realizadas da seguinte forma, sendo que, as etapas $4 \mathrm{e}$ 5 foram agrupadas para melhor desenvolvimento do mapeamento.

\section{1 - Definições das questões de pesquisa:}

As questões norteadoras do mapeamento sistemático, com objetivo de identificar discussões que vem sendo debatidas na inclusão de pessoa com deficiência na formação profissional, relacionam com as seguintes perguntas:

- Quais os assuntos abordados recentemente sobre o tema da formação profissional e a inclusão de pessoas com deficiência?

- Como as pesquisam relacionam a formação profissional da pessoa com deficiência com o mercado de trabalho?

\section{2 - Realização da pesquisa de estudos primários:}

Para realização da pesquisa, foram escolhidas as bases de dados Scielo, Scopus e Web of Science, no Portal de Periódicos da Coordenação de Aperfeiçoamento de Pessoal de Nível Superior - CAPES. Os termos utilizados para busca, que se entende que devem estar contemplados em trabalhos que tratam da temática, foram: inclusão; deficiência; formação; profissional. As palavras foram pesquisadas nas três bases de dados da seguinte forma: (inclusão) OR (deficiência) AND (formação) AND (profissional). A busca restringia a pesquisa quando utilizadas expressões como "educação profissional" ou "pessoa com deficiência". Por isso, preferiu- 
se adotar termos abrangentes que pudessem contemplar pesquisas com diferentes abordagens do assunto.

\section{3 - Utilização de critérios de inclusão e exclusão:}

Para a seleção de artigos relevantes nessa análise, adotaram-se como critérios de inclusão artigos publicados de janeiro de 2014 a dezembro de 2018, escritos em Português, Inglês ou Espanhol, de acesso gratuito e disponível para download e que tratassem da temática sobre formação profissional, educação profissional, inclusão de pessoas com deficiência e relações com o trabalho, ou sobre instituições da Rede Federal de Educação Profissional, Científica e Tecnológica.

Como critérios de exclusão, foram retirados da pesquisa resultados duplicados, artigos apenas publicados em resumo e aqueles que não atingiram os critérios de inclusão.

\section{4 e 5 - Classificação e extração de dados:}

Com a busca nas bases da Plataforma de Periódicos da CAPES dos termos indicados acima, foram retornados 303 (trezentos e três artigos) no total. Após a aplicação dos critérios de inclusão e exclusão, foram identificados apenas 11 (onze) artigos que contemplavam os assuntos abordados neste trabalho, sendo que a maioria dos demais abordava a deficiência, ou a inclusão, ou a formação profissional em outros contextos, principalmente o da saúde, e os outros não faziam parte dos critérios de inclusão. Estes onze artigos selecionados e que atendiam o objetivo proposto da pesquisa com o intuito de responder às questões de pesquisa elencadas na primeira etapa do mapeamento sistemático foram lidos na íntegra e classificados no Quadro 1:

\section{QUADRO 1: Classificação dos artigos}

\begin{tabular}{|c|c|}
\hline CATEGORIA & ARTIGO \\
\hline $\begin{array}{l}1 \text { - Reflexo na formação } \\
\text { de professores. }\end{array}$ & $\begin{array}{l}\text { - A formação profissional de pessoas com } \\
\text { deficiência e suas repercussões na formação } \\
\text { dos professores (2018); } \\
\text { - Formação e capacitação de docentes para } \\
\text { atuar com alunos com deficiência auditiva: um } \\
\text { estudo no Instituto Federal do Espírito Santo - } \\
\text { IFES (2015). }\end{array}$ \\
\hline $\begin{array}{l}2 \text { - Práticas e ações de } \\
\text { inclusão. }\end{array}$ & $\begin{array}{l}\text { - Acessibilidade digital: uma análise em portais } \\
\text { de instituições federais de educação do Brasil. } \\
\text { (2017); } \\
\text { - Assessoria para inclusão na formação }\end{array}$ \\
\hline
\end{tabular}




\begin{tabular}{|c|c|}
\hline & $\begin{array}{l}\text { profissional (2016); } \\
\text { - Pessoas com deficiência e escola: principais } \\
\text { mudanças na experiência italiana (2014). }\end{array}$ \\
\hline $\begin{array}{l}3 \text { - Perspectivas dos } \\
\text { alunos com deficiência. }\end{array}$ & $\begin{array}{l}\text { - Deficiência intelectual e educação profissional } \\
\text { (2016); } \\
\text { - Relatos de músicos cegos: subsídios para o } \\
\text { ensino de música para alunos com deficiência } \\
\text { visual (2014). } \\
\text { - Percurso Escolar de Estudantes com } \\
\text { Deficiência na Educação de Jovens e Adultos, } \\
\text { Nível Ensino Médio (2018). }\end{array}$ \\
\hline $\begin{array}{l}4 \text { - Relação da formação } \\
\text { profissional com } \\
\text { trabalho. }\end{array}$ & $\begin{array}{l}\text { - La transición a la vida activa de las personas } \\
\text { con discapacidad: expectativas familiares y } \\
\text { grado de ajuste al trabajo (2014); } \\
\text { - O adulto com deficiência intelectual: concepção de } \\
\text { deficiência e trajetória de carreira (2015); } \\
\text { - Programa educacional especializado para } \\
\text { capacitação e inclusão no trabalho de pessoas } \\
\text { com deficiência intelectual (2017). }\end{array}$ \\
\hline
\end{tabular}

Fonte: Autores, 2018.

\section{RESULTADOS E DISCUSSOES}

Os artigos escolhidos, por melhor atender ao que se propunha a investigação, serão analisados a seguir respondendo às perguntas realizadas na primeira etapa do mapeamento sistemático, separando por categorias para melhor compreensão da análise.

Questão norteadora 1: quais os assuntos abordados recentemente sobre o tema da formação profissional e a inclusão de pessoas com deficiência?

Os assuntos mais abordados nos artigos relacionados foram agrupados nas seguintes categorias: 1 - Reflexo na formação de professores; 2 Práticas e ações de inclusão; 3 - Perspectivas dos alunos com deficiência; 4 Relação da formação profissional com o trabalho. 
A categoria 1 diz repeito a como a inclusão de pessoas com deficiência na educação profissional reflete na formação de professores. $O$ artigo classificado nessa categoria, "A formação profissional de pessoas com deficiência e suas repercussões na formação dos professores" (2018), de Graciela Fagundes Rodrigues e Liliana Maria Passerino, faz uma abordagem investigativa sobre a necessidade de aprendizagem e formação sobre o atendimento educacional especializado, que vai além do conhecimento técnico, sendo por muitas vezes difícil encontrar profissionais que contemplem essas formações, como afirmam as autoras "as políticas e as ações de inclusão laboral precisam ser acompanhadas de consistentes e contínuos investimentos na qualificação dos professores da educação profissional, pois essa área não esta imune as transformações sóciohistóricas e culturais que se vivencia no presente" (2018, p. 408). O conhecimento que os professores repassam aos alunos em sua formação profissional, é fator que influencia no ingresso ao mercado de trabalho, e precisa ser transmitido de forma adequada e com qualidade, sendo fundamentais estratégias de melhoria na formação do docente da educação profissional.

O segundo artigo selecionado nessa categoria é o "Formação e capacitação de docentes para atuar com alunos com deficiência auditiva: um estudo no Instituto Federal do Espírito Santo - IFES" (2015), de Wellington Gonçalves, Verana Maria Fornaciari Gonçalves e Lilian Pittol Firme, é um estudo de caso que visa diagnosticar a formação docente no que diz respeito à inclusão de pessoas com deficiência, em um Instituto Federal. $\mathrm{O}$ artigo foi selecionado, pois trata do ensino em instituição que compõe a Rede Federal de Educação Profissional, Científica e Tecnológica, sendo importante conhecer como esse processo ocorre, servindo de parâmetros para outros estudos e instituições. Nesse sentido, tornam-se fundamentais programas de capacitação docente, visto que, o conhecimento que é ensinado reflete na formação do discente com deficiência e em sua inclusão na sociedade e no trabalho.

A categoria 2 é relativa à prática e ações de inclusão dentro da educação profissional, contendo três artigos selecionados, sendo o assunto mais abordado na seleção. $O$ artigo "Acessibilidade digital: uma análise em portais de instituições federais de educação do Brasil" (2017), de Daniel Luís Arenhardt, Tatiane Stefanel Franchi, Vânia Medianeira Flores Costa e Márcia Zampieri Grohmann, traz a acessibilidade digital como fator de melhoria na inclusão nos portais eletrônicos de Instituições Federais de Ensino do Brasil e verificam o nível dessa acessibilidade em alguns sites. $O$ resultado mostra 0 descaso com o direito da acessibilidade digital, que contribui para exclusão desses alunos. $O$ acesso a todos os meios de comunicação, sendo estes governamentais, possibilita a pessoa com deficiência informação e oportunidades como estudante e como ser social. Quando relacionamos com a educação profissional e trabalho, mostra-se de extrema importância a acessibilidade digital em mundo digital, propiciando autonomia à pessoa com deficiência.

O artigo "'Assessoria para inclusão na formação profissional" (2016), de Vanessa Cabral da Silva Pinheiro e Cristina Angélica de Aquino Carvalho 
Mascaro, apresenta ações que vem sendo desenvolvidas por um núcleo de atendimento na formação profissional, que se articula com a participação da comunidade escolar, desenvolvendo pesquisas, eventos, formação continuada de professores, apoio estudantil, adaptações de materiais e outras iniciativas que tem com objetivo "favorecer dinâmicas educacionais que reconheçam e incluam a diversidade humana, procurando garantir o acesso e permanência destes alunos na escola" (PINHEIRO; MASCARO, 2016, p. 1). Ações como essas demonstram o quanto iniciativas de inclusão dentro do espaço formal de aprendizagem são importantes para o desenvolvimento do discente com deficiência durante sua formação profissional.

O terceiro artigo, intitulado "Pessoas com deficiência e escola: principais mudanças na experiência italiana" (2014), de Giovanna Di Pasquale e Marina Maselli, mostra a prática da inclusão escolar como diretriz fundamental na educação italiana, sendo determinante para a sociabilidade da pessoa com deficiência e sua inserção na vida profissional. As autoras analisam as políticas que levaram a inclusão educacional em espaços comuns, que antes separadas em espaços especializados, segregavam os discentes com deficiência do convívio da comunidade escolar em geral, e consequentemente do mundo do trabalho, diminuindo suas oportunidades e ratificando a exclusão. Mostra-se importante a pesquisa para demonstrar que incluir deve estar relacionado ao integrar, inserir em espaços comuns com ações especializadas.

A categoria 3 é referente a perspectivas dos alunos com deficiência em relação à inclusão e formação profissional. O artigo "Deficiência intelectual e educação profissional" (2016), de Cristina Angélica de Aquino Carvalho Mascaro, analisa a inclusão de deficientes intelectuais em um curso de formação profissional, identificando fatores que contribuem para a qualidade do ensino dos mesmos, como desempenho e expectativas. A análise verifica que possuem bom desempenho e expectativa de ingressarem no mercado de trabalho dentro de sua área, apesar de obstáculos sociais e na própria instituição, que deve ter ações mais efetivas de adaptações pedagógicas e envolvimento da família, levando em conta o futuro profissional desses discentes, como a autora coloca "propostas de capacitação profissional diferenciadas para o aluno com deficiência intelectual é uma estratégia significativa para que este conquiste uma inclusão acadêmica, social e laboral" (2016, p. 358).

O artigo "Relatos de músicos cegos: subsídios para o ensino de música para alunos com deficiência visual" (2014), de Leonardo Augusto Cardoso de Oliveira e Lucia Helena Reily, aborda sobre as dificuldades que alunos com deficiência visual encontram no aprender a profissão de músico, sendo um desafio também para os docentes ensinarem a aprendizagem musical. Apesar de tratar de investigação de discentes cegos em curso de licenciatura, o estudo é relevante, pois permite entender que o processo da educação profissional inclusiva para pessoas com deficiência necessita de planejamento e práticas pedagógicas de acordo com a deficiência e o curso, não se restringindo apenas ao ensino superior, demandando também a formação especializada e contínua de docentes e a participação da família na inclusão do discente. 
O último artigo dessa categoria "Percurso Escolar de Estudantes com Deficiência na Educação de Jovens e Adultos, Nível Ensino Médio" (2016), de Graciliana Garcia Leite e Juliane Aparecida de Paula Perez Campos, faz uma análise da trajetória de estudantes com deficiência na modalidade de ensino Educação de Jovens e Adultos do ensino médio, verificando as dificuldades que encontram no percurso, mas também a expectativa que possuem em estar inserido na sociedade por meio da escola e poderem conquistar uma formação profissional para o ingresso mo mercado de trabalho, assim como ingressarem no ensino superior. Essas perspectivas de vida educacional e profissional precisam estar apoiadas em ações de inclusão e integração na comunidade escolar, que podem "resultar em processos de escolarização menos fragmentados, que convergiriam, por sua vez, em propostas educacionais mais adequadas às suas demandas" (LEITE; CAMPOS, 2016, p. 30), oportunizando o discente com deficiência escolher seu futuro tendo uma educação de qualidade como base.

A categoria 4, última da análise, refere-se aos artigos que abordam de forma mais direta a relação da formação profissional com o trabalho. $\mathrm{O}$ artigo "La Transición a la Vida Activa de las Personas con Discapacidad: Expectativas Familiares y Grado de Ajuste al Trabajo", de Ana Riaño-Galán, Alejandro Rodríguez-Martí, Rosa García-Ruiz e Emilio Álvarez-Arregui, faz um estudo com alunos da Europa, demonstrando a importância da qualificação profissional para a inserção no mercado de trabalho com qualidade educacional, proporcionando qualidade de vida e inclusão social. A pesquisa se restringiu em investigar deficientes intelectuais, mas os resultados servem de parâmetro para outras deficiências. $O$ artigo traz a importância da família no incentivo ao discente, e que isso reflete em seu desempenho melhorando sua sociabilidade e atitude na escolarização e no trabalho, percebendo a importância do engajamento de toda a comunidade escolar no desenvolvimento deste, que passa a ter expectativa de vida e perspectivas de ingresso laboral de maneira adequada.

O artigo "O adulto com deficiência intelectual: concepção de deficiência e trajetória de carreira" (2015), de Larissa Schikovski Angonese, lasmin Zanchi Boueri e Andréia Schmidt, mostra como a precarização do ensino profissional pode refletir no ambiente de trabalho, sendo necessárias ações que permitam uma inclusão total dentro do trabalho e a percepção de inclusão de todos. A pesquisa revela que aqueles que conseguem inserir no mercado de trabalho o encaram como aspecto de sociabilidade e independência financeira, mas que "persistem várias concepções negativas sobre suas capacidades e sobre sua possibilidade real de manter uma vida independente da família, ou de ascender profissionalmente, dentro ou fora da empresa" (ANGONESE; BOUERI; SCHMIDT, 2015, p. 32), mostrando-se necessário a importância da escola, seja ela propedêutica ou profissional, como transição para esse ingresso, e que sejam revistas as práticas de ensino no sentido de expandir suas habilidades e possibilitarem de alcançar melhores empregos.

O último artigo da categoria 4, "Programa educacional especializado para capacitação e inclusão no trabalho de pessoas com deficiência intelectual" (2017), de Annie Gomes Redig a Rosana Glat, analisa as legislações que tratam da inclusão profissional do deficiente intelectual, e 
aborda a estratégia "trabalho customizado", que "Esta proposta parte do pressuposto de que pessoas com deficiência, mesmo as que apresentam grande comprometimento, são capazes de produzir e contribuir com a empresa ou instituição se houver adaptações e/ou suportes adequados em seu local de trabalho" (REDIG; GLAT, 2017; p. 339), obtendo bons resultados em pesquisa realizada. Também destaca a importância da educação especial na vida da pessoa com deficiência, pois uma vez inserido, passa a se sentir parte da sociedade, reconhece-se como sujeito, e isso se realiza em autonomia e independência, refletindo no desempenho no trabalho. Assim, a educação profissional deve cumprir o papel de incluir social e educacionalmente, preparando para formar efetivamente para a vida futura.

Questão norteadora 2: como as pesquisam relacionam a formação profissional da pessoa com deficiência com o mercado de trabalho?

Os artigos analisados demonstram a importância da oferta de uma educação profissional de qualidade e inclusiva para a preparação da pessoa com deficiência para o mundo do trabalho.

Criar ações dentro dos espaços, que enfoque o discente, suas capacidades e explore suas habilidades, além de programas de formação continuada para docentes, envolvimento da comunidade escolar, e aqui destacamos a família, formam uma cadeia de apoio, incentivo e integração que fortalece a vida social do discente com deficiência, o comprometimento, o desempenho e consequentemente uma vida mais autônoma, refletindo uma pessoa independente e com atitude no ambiente de trabalho, além do conhecimento que o habilita a competir por uma vaga com mais qualidade em sua área.

Os trabalhos ressaltam avanços já conquistados, mas não deixam de fazer críticas à falta de compromisso e de ações para melhoria da educação profissional, etapa essa, que quando cursada, torna-se mais uma oportunidade e perspectiva de ingresso no mercado de trabalho em uma sociedade exclusiva.

\section{CONSIDERAÇÕES FINAIS}

Apesar do número crescente de contratação inclusiva na iniciativa do setor público e privado, na prática, os direitos da pessoa com deficiência ainda são desrespeitados quando as empresas tentam adequar de forma discriminatória a deficiência da pessoa com a demanda da sua produtividade,

deixando de fora do mercado outros profissionais com deficiências mais severas. De acordo com Frigotto (1989) o trabalho é parte da realização humana e este depende de uma transformação social com foco na visão coletiva do trabalho. O campo da educação profissional, como espaço de acolhimento e de formação profissional, não pode ser indiferente a este processo, pois o caminho para a mudança desse paradigma começa na 
educação a partir de uma atitude de inclusão por meio de políticas e ações de integração da pessoa com deficiência.

A análise deste levantamento bibliográfico permitiu apontar alguns fatores que contribuem para exclusão da pessoa com deficiência no acesso à sua qualificação profissional e consequentemente ao mercado de trabalho. As dificuldades surgem desde a infraestrutura inadequada à demanda e qualificação dos profissionais na educação profissional e inclusiva. A exclusão também passa pela acessibilidade digital, fator que gera autonomia e democratização do acesso às tecnologias.

O mapeamento siatemático realizado, identificou onze artigos que contemplassem os critérios determinados, em que os assuntos abordados, agrupados em categorias, foram praticamente de forma igualitária, sendo que todos ressaltavam a importância da oferta de uma educação de qualidade e inclusiva para o desenvolvimento do potencial do discente com deficiência. Destaque também para a integração da comunidade escolar e, principalmente, da família nesse processo de ensino, assim como o fortalecimento de políticas de formação continuada aos docentes que atuam com esse público.

As perspectivas que o discente com deficiência da educação profissional tem ao ingressar em um curso, aspirando a uma vaga de trabalho em sua área, crescem quando há inclusão. Incluir é desenvolver um ser emancipado e capacitado, com reflexos em sua atuação como sujeito de sua história e no mundo do trabalho. A eficiência de uma política pública de inclusão na educação profissional requer também uma mudança do modelo social excludente para um modelo baseado na diversidade humana em que os sistemas não tentem adaptar as pessoas às suas exigências, mas ao contrário, os sistemas de ensino e o mercado se adaptem às necessidades dos deficientes. Que no futuro, possamos vislumbrar uma inclusão que não passe pela obrigatoriedade, mas que seja parte inerente à sociedade.

\section{REFERÊNCIAS}

ANGONESE, L. S.; BOUERI, I. Z.; SCHMIDT, A. O adulto com deficiência intelectual: concepção de deficiência e trajetória de carreira. Revista Brasileira de Orientação Profissional, São Paulo, v. 16, n. 1, p. 2334, jun. 2015.2 Disponível em http://pepsic.bvsalud.org/pdf/rbop/v16n1/04.pdf. Acesso em 05 dez. 2018.

ARENHARDT, D. L. et al. Acessibilidade digital: uma análise em portais de instituições federais de educação do Brasil. Arquivos Analíticos de

Políticas Educativas, Santa Catarina, v. 25, n. 33, p. 1-28, 2017. DOI: http://dx.doi.org/10.14507/epaa.25.2639. Disponível em: https://epaa.asu.edu/ojs/article/view/2639. Acesso em: 05 dez. 2018.

BRASIL. [Constituição (1988)]. Constituição da República Federativa do Brasil de 1988. Brasília, DF: Presidência da República, 1988. Disponível em: 
http://www.planalto.gov.br/ccivil_03/Constituicao/Constituicao.htm.

Acesso em: 02 dez. 2018.

Decreto no. 3.298, de 20 de dezembro de 1999. Regulamenta a Lei no. 7.853, de 24 de outubro de 1989, dispõe sobre a Política Nacional para a Integração da Pessoa Portadora de Deficiência, consolida as normas de proteção, e dá outras providências. Diário Oficial da União, Brasília, DF, 1999. Disponível em: http://www.planalto.gov.br/ccivil 03/decreto/D3298.htm. Acesso em: 03 dez. 2018.

Decreto no 5.154, de 23 de julho de 2004. Regulamenta $\circ \S 2 \stackrel{\underline{\underline{0}}}{\text { do }}$ art. 36 e os arts. 39 a 41 da Lei $n=9.394$, de 20 de dezembro de 1996, que estabelece as diretrizes e bases da educação nacional, e dá outras providências. Diário Oficial da União, Brasília, DF, 2004. Disponível em: http://www.planalto.gov.br/ccivil 03/ Ato2004-2006/2004/Decreto/D5154.htm. Acesso em: 05 dez. 2018.

Lei no. 9.934, de 20 de dezembro de 1996. Estabelece as diretrizes e bases da educação nacional. Brasília, DF, 1996. Disponível em: http://www.planalto.gov.br/ccivil_03/LEIS/L9394.htm. Acesso em: 02 dez. 2018.

Lei 10.172, de 9 de janeiro de 2001. Aprova o Plano Nacional de Educação e dá outras providencias. Diário Oficial da União. Brasília, DF, 2001a. Disponível em: http://www.planalto.gov.br/ccivil 03/leis/leis 2001//10172.htm. Acesso em: 03 dez. 2018.

. Ministério da Educação. Secretaria de Educação Especial. Diretrizes

nacionais para a educação especial na educação básica. Brasília, DF: Ministério da Educação, 2001b. Disponível em: http://portal.mec.gov.br/seesp/arquivos/pdf/diretrizes.pdf. Acesso em: 03 dez. 2018.

Ministério da Educação. Secretaria de Educação Profissional e Tecnológica. Programa TEC NEP: Educação, tecnologia e profissionalização para pessoas com necessidades educativas especiais. Brasília, DF: Ministério da Educação, 2005. Disponível em: http://portal.mec.gov.br/setec/arquivos/pdf/anaisseminarionacionaltecnep2005 .pdf. Acesso em: 03 dez.. 2018.

Ministério do Trabalho. Relação Anual de Informações Sociais ano 2017. Brasília: MTE, 2017. Disponível em: http://pdet.mte.gov.br/rais. Acesso em: 07 dez. 2018.

CAIADO, K. R. M. Aluno deficiente visual na escola: lembranças e depoimentos. Campinas. PUC: Autores Associados, 2003.

COSTA, M. A.; COUTINHO, E. H. L.. A formação de professores para a educação profissional e o notório saber: uma ponte para o passado. In: IV Colóquio Nacional e I Colóquio Internacional: A produção do conhecimento em educação profissional: a reforma do ensino médio e suas implicações para a educação profissional. Natal, RN: IFRN, 2017. p. 1-12. Disponível

em: 
https://ead.ifrn.edu.br/coloquio/anais/2017/trabalhos/eixo1/E1A4.pdf. Acesso em: 05 dez. 2018.

DI PASQUALE, G.; MASELLI, M. Pessoas com deficiência e escola: principais mudanças na experiência italiana. Educação e Realidade, Porto

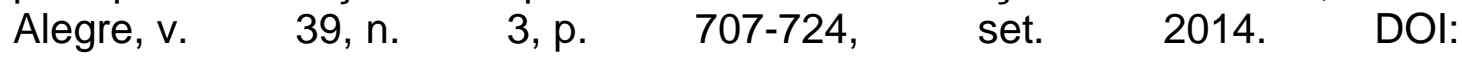
http://dx.doi.org/10.1590/S2175-62362014000300005. Disponível em: http://www.scielo.br/scielo.php?script=sci_arttext\&pid=S217562362014000300005\&lng=en\&nrm=iso. Acesso em: 05 dez. 2018.

FRIGOTTO, G. Trabalho, conhecimento, consciência e a educação do trabalhador: impasses teóricos e práticos. In: GOMEZ, C. M. et al. Trabalho e conhecimento: dilemas na educação do trabalhador. São Paulo: Cortez; autores Associados, 1989. p. 13-26.

GONCALVES, W.; GONCALVES, V. M. F.i; FIRME, L. P. Formação e capacitação de docentes para atuar com alunos com deficiência auditiva: um estudo no Instituto Federal do Espírito Santo - IFES. Ensaio: Avaliação e Políticas Públicas em Educação, Rio de Janeiro , v. 24, n. 93, p. 866889, dez. 2016. DOI: http://dx.doi.org/10.1590/S0104-40362016000400005. Disponível em: http://www.scielo.br/pdf/ensaio/v24n93/1809-4465-ensaio-2493-0866.pdf. Acesso em: 05 dez. 2018.

JANNUZZI, G. M. Prefácio. A educação do deficiente no Brasil: dos primórdios ao início do século XXI. Campinas: Autores Associados, 2004.

LEITE, G. G.; CAMPOS, J. A. P. P. Percurso Escolar de Estudantes com Deficiência na Educação de Jovens e Adultos, Nível Ensino Médio. Revista Brasileira de Educação Especial, Bauru, v. 24, n. 1, p. 17-32, mar. 2018. DOI: http://dx.doi.org/10.1590/s1413-65382418000100003. Disponível em: http://www.scielo.br/pdf/rbee/v24n1/1413-6538-rbee-24-01-0017.pdf. Acesso em: 05 dez. 2018.

MARQUES, C. A. Integração: uma via de mão dupla na cultura e na sociedade. In: MANTOAN, M. T. E. (Org.). A integração de pessoas com deficiência: contribuições para uma reflexão sobre o tema. São Paulo: Memnon, 1997. p. 18-23.

MASCARO, C. A. A. C. Deficiência Intelectual e Educação Profissional. Journal of Research in Special Educational Needs, England, v. 16, n. 1, p. 355-359, 2016. DOI: https://doi.org/10.1111/1471-3802.12296. Disponível em: https://onlinelibrary.wiley.com/doi/full/10.1111/1471-3802.12296. Acesso em: 05 dez. 2018.

MOURA, D. H.; GARCIA, S.; RAMOS, M. Educação profissional técnica de nível médio integrada ao ensino médio: documento-base. Brasília, Secretaria de Educação Profissional e Tecnológica, 2007. Disponível em: http://portal.mec.gov.br/setec/arquivos/pdf/documento base.pdf. Acesso em: 05 dez. 2018.

NASCIMENTO, F. C.; FARIA, R.. A questão da inclusão na rede federal de educação profissional, científica e tecnológica, a partir da ação TEC NEP. In: NASCIMENTO, F. C.; FLORINDO, G. M. F.; SILVA, N. S. (Orgs.). Educação profissional e tecnológica inclusiva: um caminho em construção. Brasília: Instituto Federal de Educação, Ciência e Tecnologia de Brasília, 2013. p. 13- 
23.

Disponível

em:

http://revistaeixo.ifb.edu.br/index.php/editoraifb/article/view/185/86. Acesso em: 02 dez. 2018.

OLIVEIRA, L. A. C.; REILY, L. H. Relatos de músicos cegos: subsídios para o ensino de música para alunos com deficiência visual. Revista Brasileira de Educação Especial, Marília, v. 20, n. 3, p. 405-420, set. 2014. DOI: http://dx.doi.org/10.1590/S1413-65382014000300007. Disponível em: http://www.scielo.br/pdf/rbee/v20n3/06.pdf. Acesso em: 05 dez. 2018.

PETERSEN, K., FELDT, R., MUJTABA, S. and MATTSSON, M. Systematic mapping studies in software engineering. In: 12th International Conference on Evaluation and Assessment in Software Engineering, 2008, p. 68-77. Disponível em: https://dl.acm.org/citation.cfm?id=2227123. Acesso em 02 dez. 2018.

PINHEIRO, V. C. da S; MASCARO, C. A. de A. C. Assessoria para inclusão na formação profissional. Journal of Research in Special Educational Needs, vol.16, p.197-200, ago. 2016. Disponível em: https://onlinelibrary.wiley.com/doi/epdf/10.1111/1471-3802.12141. Acesso em: 05 dez. 2018.

REDIG, A. G.; GLAT, R. Programa educacional especializado para capacitação e inclusão no trabalho de pessoas com deficiência intelectual. Ensaio: Avaliação e Políticas Públicas em Educação, Rio de Janeiro, v. 25, n. 95, p. 330-355, abr. 2017. DOI: http://dx.doi.org/10.1590/s0104-40362017002500869.Disponível em: http://www.scielo.br/pdf/ensaio/v25n95/1809-4465-ensaio-S0104 40362017002500869.pdf. Acesso em 05 dez. 2018.

RIANO-GALAN, A. et al . La transición a la vida activa de las personas con discapacidad: expectativas familiares y grado de ajuste al trabajo. Revista Brasileira de Educação Especial, Marília, v. 20, n. 2, p. 283302, jun. 2014. DOI: http://dx.doi.org/10.1590/S1413-65382014000200010. Disponível em: http://www.scielo.br/pdf/rbee/v20n2/10.pdf. Acesso em: 05 dez. 2018.

ROCHA, F. G.; NASCIMENTO, B. A. R.; NASCIMENTO, E. F. V. C. Um modelo de mapeamento sistemático para a Educação. FUCAMP: Cadernos, v. 17, p. 1-6, 2018. Disponível em: http://www.fucamp.edu.br/editora/index.php/cadernos/article/view/1180.

Acesso em: 01 dez. 2018

ROCHA, J. S.; AMORIM, A; FERREIRA, M. C. A, LOPES, M. M. A inclusão escolar de jovens e adultos com deficiências: Ações gestoras necessárias. Brazilian Journal of Education, Technology and Society, v.11, n.3, jul.set., p.506-521, 2018. Disponível em: www.brajets.com/index.php/brajets/article/download/481/284. Acesso em: 02 dez. 2018.

RODRIGUES, G. F.; PASSERINO, L. M. A formação profissional de pessoas com deficiência e suas repercussões na formação dos professores. Revista Brasileira de Educação Especial, Bauru, v. 24, n. 3, p. 407426, set. 2018. DOI: http://dx.doi.org/10.1590/s1413-65382418000300007. 
Disponível em: http://www.scielo.br/pdf/rbee/v24n3/1413-6538-rbee-24-030407.pdf. Acesso em 05 dez. 2018.

SCHWARZ, A.; HABER, J. Cotas: como vencer os desafios da contratação de pessoas com deficiência. São Paulo: I. Social, 2009. Disponível em: https://vidamaislivre.com.br/uploads/isocial/livro-cotas.pdf. Acesso em 05 dez. 2018.

TEZANI, T. C. R. Os caminhos para a construção da escola inclusiva: a relação entre a gestão escolar e o processo de inclusão. Dissertação (Mestrado em Educação), Universidade Federal de São Carlos, São Carlos, SP, $2004 . \quad$ Disponível em: https://repositorio.ufscar.br/bitstream/handle/ufscar/2638/DissTCRT.pdf?sequ ence $=1$ \&isAllowed=y. Acesso em: 02 dez. 2018. 